\title{
OS ESPAÇOS LIVRES PÚBLICOS DA REGIÃO METROPOLITANA DE BELO HORIZONTE (MG): ÁREA CONURBADA DO VETOR OESTE
}

\author{
THE PUBLIC OPEN SPACES OF THE METROPOLITAN REGION OF \\ BELO HORIZONTE (MG): WEST VECTOR CONURBATION AREA
}

\author{
Marieta Cardoso Maciel* \\ Natalia Achcar Monteiro Silva** \\ Mirelli Borges Medeiros*** \\ Priscila Schiavo Gomes da Costa**** \\ Renata Carolina Fraga Ribeiro*****
}

\section{RESUMO}

Este estudo apresenta um panorama geral das pesquisas desenvolvidas pelo Laboratório da Paisagem da Escola de Arquitetura da Universidade Federal de Minas Gerais em relação à participação na rede nacional do projeto Quadros do Paisagismo no Brasil. A ênfase está nas discussões atuais sobre os espaços livres das bordas da área conurbada de Belo Horizonte (MG), para as quais já foi desenvolvida a análise do Vetor Norte e, em processo de execução, a do Vetor Oeste. As etapas da pesquisa se iniciam com a revisão bibliográfica e documental, sequenciada pelo levantamento e pela identificação prévia das tipologias dos espaços livres da mancha conurbada, seguida do trabalho de campo para confirmação das áreas e, por fim, a triangulação das informações e os resultados.

Palavras-chave: Forma urbana. Espaços livres de uso público. Área conurbada da Região Metropolitana de Belo Horizonte. \footnotetext{
Urbanas pela Faculdade de Arquitetura e Urbanismo da Universidade de São Paulo (FAUUSP). Professora titular e coordenadora do Mestrado Interdisciplinar em Ambiente Construído e Patrimônio Sustentável (MACPS) da Escola de Arquitetura da UFMG.

CV: http://lattes.cnpq.br/8723102060660900

** Arquiteta urbanista, mestre em Ambiente Construído e Patrimônio Sustentável pela Universidade Federal de Minas Gerais (MACPS-UFMG), pesquisadora no Laboratório de Paisagem do Departamento de Urbanismo da Escola de Arquitetura da UFMG, docente no Centro Universitário Metodista Izabela Hendrix e no Centro Universitário de Belo Horizonte (UNIBH). CV: http://lattes.cnpq.br/7696368723118274

*** Arquiteta urbanista pela Universidade Federal de Minas Gerais (UFMG). Pós-graduação lato sensu em Plantas Ornamentais e Paisagismo pela Universidade Federal de Lavras (UFL) e em Sistemas Tecnológicos e Sustentabilidade Aplicados ao Ambiente Construído pela UFMG. Mestranda em Ambiente Construído e Patrimônio Sustentável (MACPS) da Escola de Arquitetura da UFMG.

CV: http://lattes.cnpq.br/2505986706125268

**** Aluna de Arquitetura e Urbanismo e bolsista do Laboratório da Paisagem da Escola de Arquitetura da Universidade Federal de Minas Gerais (EA-UFMG).

CV: http://lattes.cnpq.br/3853619815883019

***** Aluna de Arquitetura e Urbanismo na Universidade Federal de Minas Gerais (UFMG). Intercâmbio na University of Portsmouth, cursando BA (Hons) Architecture. Bolsista do Laboratório da Paisagem da Escola de Arquitetura da UFMG.

CV: http://lattes.cnpq.br/8968899994077645
}

Arquiteta urbanista pela Universidade Federal de Minas Gerais (UFMG). Doutora em Estruturas Ambientais 
Marieta Cardoso Maciel, Natalia Achcar Monteiro Silva, Mirelli Borges Medeiros,

Priscila Schiavo Gomes da Costa e Renata Carolina Fraga Ribeiro

\section{ABSTRACT}

This study presents an overview of a research project conducted by the UFMG - School of Architecture, Landscape Laboratory, regarding its participation in the national network of the Quapá project. The emphasis is on the current discussions about open spaces on the outskirts of the conurbation area of Belo Horizonte/MG; the North Vector analysis had already been carried out, and the West Vector's is currently in development process. The stages of the research begin with the bibliographic and documentary review, followed by a survey and prior identification of typologies of open spaces in the conurbation area, once again followed by a field trip to confirm the areas and, finally, the triangulation of the information and results. Keywords: Urban form. Open space of public use. Conurbation area of Belo Horizonte Metropolitan Region.

\section{INTRODUÇÃO}

As cidades são formadas por espaços edificados e espaços livres de edificações, todos interconectados, que se transformam ao longo do tempo. Muitas vezes a forma urbana é derivada de políticas de planejamento urbano; outras vezes, a ocupação ocorre de forma indiscriminada e sem regras claras, o que gera os assentamentos urbanos precários. Fatores históricos e econômicos são, talvez, os principais responsáveis pela formação e condução da expansão urbana que, em geral, não se restringe aos limites geopolíticos dos municípios. Em regiões metropolitanas, por exemplo, é recorrente que a área urbanizada extrapole esses limites e conduza à formação de áreas conurbadas que englobam vários municípios.

Compreende-se por conurbação os tecidos urbanos de duas aglomerações que se expandem em sentidos convergentes, culminando no processo de formação de uma única e grande mancha urbana. A formação desse fenômeno caracteriza a paisagem urbana de Belo Horizonte e sua relação com os municípios adjacentes. É no contexto da área de conurbação urbana que se pretende investigar o sistema de espaços livres e sua relação com a forma urbana. Entende-se que os espaços livres urbanos desempenham importantes funções no contexto urbano, tais como a realização de encontros e a possibilidade da circulação, sendo tão importantes quanto os espaços edificados na estruturação urbana. (DEL RIO, 1990 apud MACIEL et al., 2014, p. 4).

As pesquisas desenvolvidas pelo Laboratório da Paisagem da Escola de Arquitetura da Universidade Federal de Minas Gerais (LAP UFMG) fazem parte de uma rede nacional de estudos sobre o paisagismo urbano centralizada pelo Projeto Quadro do Paisagismo no Brasil (Quapá), desenvolvido desde 1994 pelo Departamento de Projeto da Faculdade de Arquitetura da Universidade de São Paulo (FAUUSP).

O núcleo de Belo Horizonte tem atuado no projeto com diversas pesquisas, desenvolvidas desde 2008, considerando as abordagens específicas para as diferentes escalas de análise e os diversos graus de aprofundamento em função da maior ou menor possibilidade concreta de obtenção de informações. Sendo assim, iá foram realizadas as seguintes pesquisas: "Os sistemas de espaços livres e a constituição da esfera pública contemporânea no Brasil - Quapá-SEL", de acordo com os termos do Edital 01/2006 Universal da Fundação de Amparo à Pesquisa do Estado de Minas Gerais (FAPEMIG); "Os elementos tipo-morfológicos das bordas metropolitanas de 
Belo Horizonte", Edital 01/2009 Universal FAPEMIG; "Sistemas de espaços livres e forma urbana da cidade brasileira na contemporaneidade - Quapá-SEL II", Edital 01/2011 Universal FAPEMIG, com foco no Vetor Norte da Região Metropolitana de Belo Horizonte (RMBH). Atualmente, desenvolve-se a pesquisa "Sistemas de espaços livres e forma urbana da cidade brasileira na contemporaneidade - Quapá-SEL II: Vetor Oeste da Região Metropolitana de Belo Horizonte/MG", implantada no termo do Edital 01/2013 Universal FAPEMIG.

O projeto "Os Sistemas de Espaços Livres e a Constituição da Esfera Pública Contemporânea no Brasil", desenvolvido com a participação de diversos laboratórios e grupos de pesquisa de instituições superiores públicas e privadas de todas as regiões do Brasil, busca identificar os sistemas de espaços livres da cidade contemporânea brasileira e a constituição da esfera de vida pública a eles relacionada. Seus objetivos compreendem aprofundar as discussões sobre os espaços livres existentes nas cidades; verificar esses espaços como representantes de uma condição da vida cultural urbana; analisar como os poderes públicos urbanos atuam em relação a eles; construir, a partir da vinculação entre espaços livres e vida pública, um referencial interpretativo da contemporaneidade urbana brasileira.

A pesquisa realizada em Belo Horizonte levantou os principais aspectos sobre os sistemas em geral e sua aplicação no conceito de paisagem. O resultado é a somatória de conhecimento, esforço e dedicação de todos os membros da equipe do LAP UFMG, coordenada pela professora doutora Staël de Alvarenga Pereira Costa. Este trabalho contou com a experiência profissional e científica das pesquisadoras associadas, professoras doutoras Maria Cristina Villefort Teixeira e Marieta Cardoso Maciel.

Na pesquisa Quapá-SEL II núcleo BH, foram identificados e mapeados os diversos tipos de espaços livres e estabeleceu-se o sistema de espaços livres urbanos existentes. As potencialidades ecológicas para a conservação dos recursos naturais e o equilíbrio dos processos naturais na área urbana foram todos baseados em conceitos contemporâneos da paisagem.

O presente artigo apresenta a investigação "Sistemas de espaços livres e forma urbana da cidade brasileira na contemporaneidade - Quapá-SEL II", na qual são identificados os espaços livres e a sua relação com a forma urbana da RMBH. A partir dessa análise dos espaços livres, busca-se construir um referencial metodológico das relações entre os espaços livres (públicos e privados), os espaços edificados (públicos e privados) e a forma urbana das cidades brasileiras na contemporaneidade. Logo, pressupõe-se que os espaços livres podem ser considerados elementos estruturantes da forma da cidade. Assim, os objetivos gerais deste trabalho são:

- investigar as relações entre os sistemas de espaços livres e a produção da forma urbana;

- analisar a pertinência dos fundamentos de planejamento do sistema de espaços livres e a sua suficiência para a compreensão e proposição do complexo quadro urbano contemporâneo da cidade; 
Marieta Cardoso Maciel, Natalia Achcar Monteiro Silva, Mirelli Borges Medeiros,

Priscila Schiavo Gomes da Costa e Renata Carolina Fraga Ribeiro

- investigar as bases conceituais de entendimento dos espaços livres;

- contribuir para a elaboração, em âmbito nacional, de princípios gerais de políticas, planos e implantações de espaços livres mais atentos à heterogênea realidade urbana brasileira;

- construir um referencial de método para a análise quantitativa e qualitativa das relações entre espaços livres e forma urbana;

- estabelecer critérios de avaliação dessas relações.

Seguem os objetivos específicos:

- analisar a distribuição do sistema de espaços livres na área conurbada de cada vetor da RMBH segundo variáveis ambientais, paisagísticas, legais e de estrutura urbana;

- definir a tipologia dos espaços livres identificados na área conurbada dos vetores da $\mathrm{RMBH}$;

- elaborar, em âmbito local, princípios gerais de políticas, planos e implantações de espaços livres mais atentos à heterogênea realidade urbana da área conurbada da RMBH;

- consolidar o núcleo de estudos da paisagem na RMBH.

\section{A ESTRUTURA URBANA DE BELO HORIZONTE EM 2015}

No plano de 1895, de Aarão Reis, a cidade de Belo Horizonte foi estruturada por um anel, chamado avenida 17 de Dezembro (hoje, avenida do Contorno), que circundava a zona urbana, na qual foram implantadas as atividades residenciais e administrativas. O principal eixo simbólico da nova capital ocorria no sentido norte-sul, centralizado pela praça Sete de Setembro, que também conectava o eixo viário na direção leste-oeste. Atualmente, essa praça exerce a função de principal centralidade, juntamente com a extensa área de seu entorno, classificada como o hipercentro metropolitano. Dois outros centros localizam-se nas regiões oeste e norte, no Barreiro e Venda Nova, respectivamente.

Quase todo o território do município já se encontra ocupado (figura 1), na sua grande maioria, pelo uso residencial. A ocupação residencial também ocorre na porção do extremo sul do município, nas áreas de média declividade, constituindo unidades de maior porte, implantadas em lotes de grande dimensão e baixa densidade ocupacional. Nas áreas de alta declividade e nas margens dos cursos d'água, houve a apropriação por população de baixa renda, constituindo favelas, com ocupação pontual e distribuídas na malha urbana.

Os principais eixos de deslocamento da cidade são constituídos pelos vetores Oeste e Norte, sobre os quais estão implantadas as rodovias e o eixo ferroviário, consolidados desde a implantação da capital. Os eixos de expansão no sentido oeste levam à área industrial e são os principais vetores de expansão consolidados a partir da construção 


\section{Evolução da Mancha de Ocupação Populacional \\ Belo Horizonte - 1918-2007}

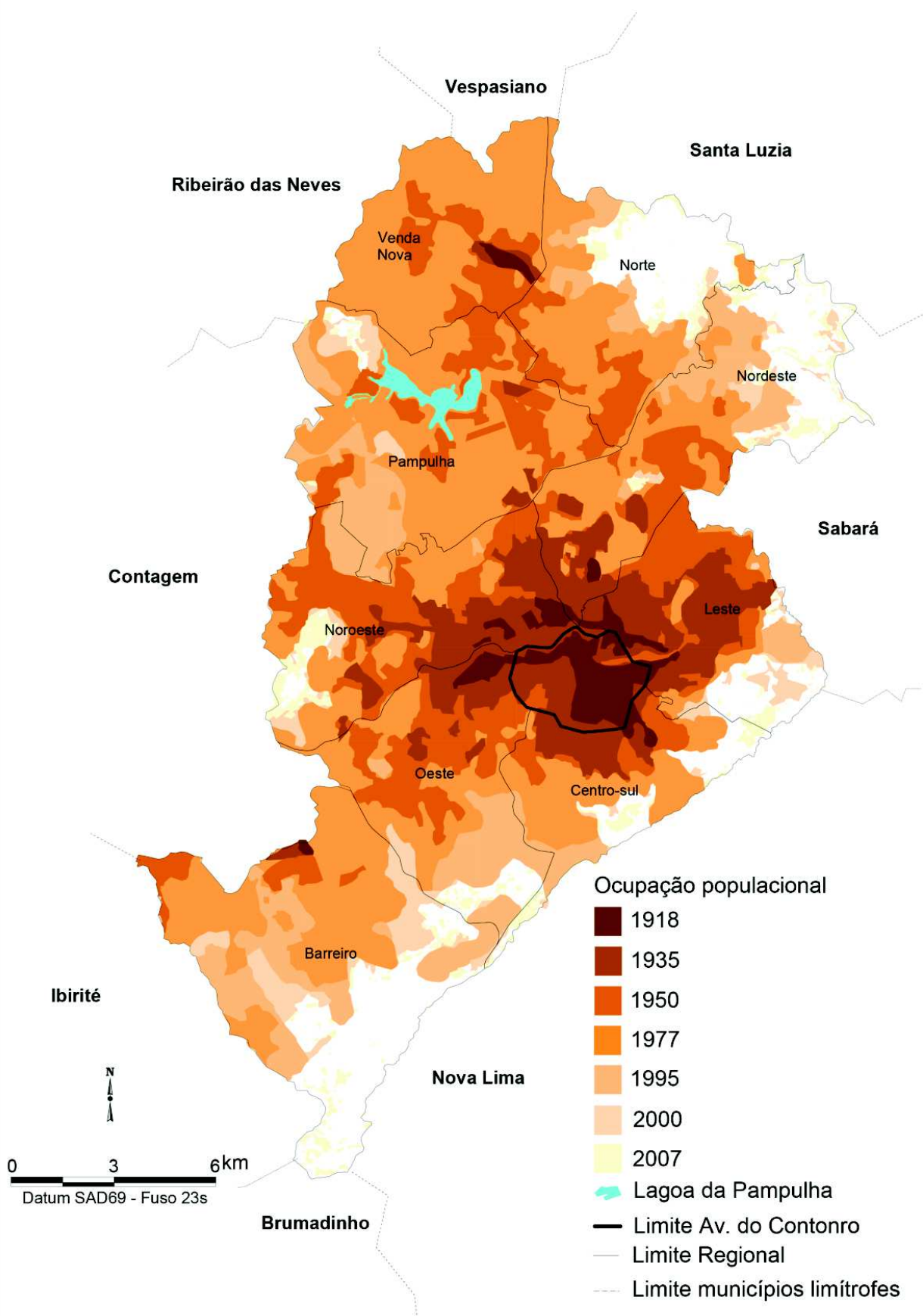

Figura 1 Mapa com a evolução da mancha urbana de ocupação de Belo Horizonte (MG) entre 1918 e 2007. Fonte: Prefeitura de Belo Horizonte (PBH). Disponível em: <http://portalpbh.pbh.gov.br/pbh/ecp/ comunidade.do? evento $=$ portlet\&pldPlc $=$ ecpTaxonomiaMenuPortal\&app = estatisticaseindicadores\&lang $=$ pt_BR\&pg $=7742 \& t a x=20038>$. Acesso em: 28 mai. 2015. 
da cidade industrial na década de 1930. Observa-se, também, a expansão direcionada para áreas do setor norte do município, induzida pela implantação de indústrias extrativas de calcário para a produção de cimento a partir da década de 1960, reforçada pela construção do aeroporto internacional na década de 1980 e pela cidade administrativa do governo estadual em 2010. No eixo norte também se observam ocupações de condomínios destinados à alta e baixa renda.

Outros eixos localizados no sentido noroeste e nordeste são indutores das ocupações periféricas e abrigos da população de baixa renda. $\bigcirc$ eixo de expansão sul, constituído pela rodovia Belo Horizonte-Rio de Janeiro (BR-040), é ocupado, sobretudo, por condomínios fechados que abrigam famílias de alto poder aquisitivo em residências unifamiliares.

Os espaços livres públicos encontram-se pulverizados na mancha urbana e os de maiores dimensões localizam-se na serra do Curral, que atua como barreira à expansão urbana, são classificados como áreas de preservação ambiental. A figura 2 resume a situação da estrutura urbana do município em 2015.

Da época de sua inauguração, 1897, até 2010, Belo Horizonte passou por transformações significativas em seu espaço físico, que refletem diretamente os processos de cunho socioeconômico, político e cultural que aconteceram ao longo de sua história. Argumenta-se, assim, que esse processo aponta um descaso do poder público com relação aos seus espaços livres públicos, primeiramente com a ocupação e canalização dos córregos, posteriormente com a baixa taxa de implementação, proteção e criação de "áreas verdes" e finalmente tratando-as como áreas residuais no tecido urbano.

Por meio das análises realizadas, percebe-se que a relação existente entre os espaços livres e os impactos gerados pela implantação de uma avenida é direta. As avenidas criadas a partir da canalização de córregos são exemplos de como a administração pública resolve os problemas urbanos sem levar em conta os aspectos ambientais e sociais dos espaços livres, antes em sua forma natural.

Verifica-se que, no período de 1988 a 2010, a implantação de parques e praças teve aumento considerável, e a presença desses espaços permeia todas as regiões da cidade. Esse fato se deve, possivelmente, à crise ambiental verificada nos últimos anos e à participação popular crescente - devido à exigência de leis - nas decisões relativas à administração da cidade. Entretanto, é evidente que nunca houve a intenção de estruturá-los como um sistema, tendo em vista a sua fragmentação na cidade.

Com o avanço do processo de metropolização e a promulgação da Lei Complementar Federal No 14 de 1973, foram definidas regiões metropolitanas, entre elas, a RMBH. É constituída por 34 municípios e população total de 5,8 milhões de habitantes. (IBGE, 2010). Os municípios são: Baldim, Belo Horizonte, Betim, Brumadinho, Caeté, Capim Branco, Confins, Contagem, Esmeraldas, Florestal, Ibirité, Igarapé, Itaguara, Itatiaiuçu, Jaboticatubas, Juatuba, Lagoa Santa, Mário Campos, Mateus Leme, Matozinhos, Nova Lima, Nova União, Pedro Leopoldo, Raposos, Ribeirão das Neves, Rio Acima, Rio Manso, Sabará, Santa Luzia, São Joaquim de Bicas, São José da Lapa, Sarzedo, Taquaraçu de Minas e Vespasiano. 


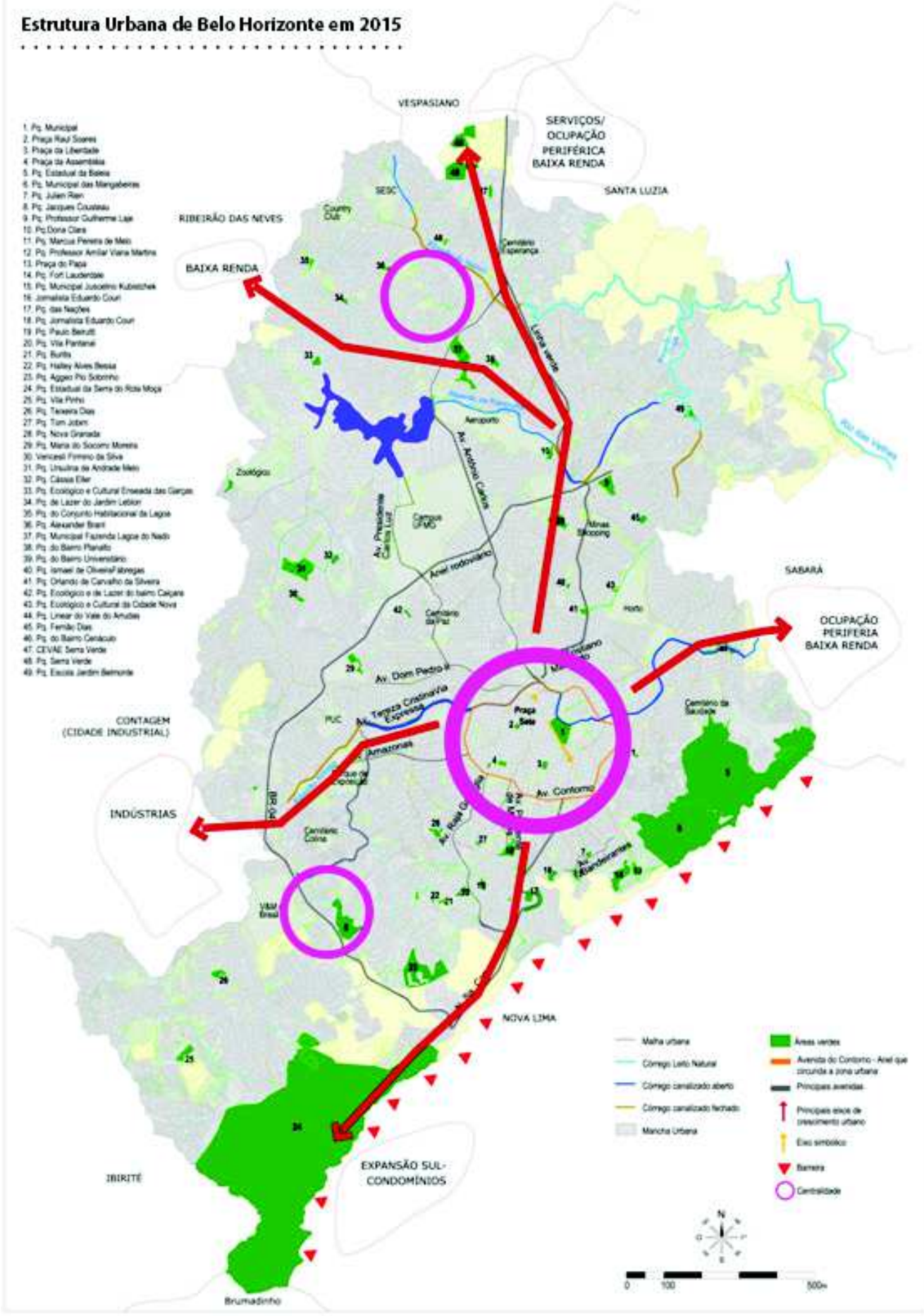

Figura 2 Mapa da estrutura urbana de Belo Horizonte em 2015.

Fonte: Elaborada pela equipe do LAP UFMG, 2015. 
Marieta Cardoso Maciel, Natalia Achcar Monteiro Silva, Mirelli Borges Medeiros,

Priscila Schiavo Gomes da Costa e Renata Carolina Fraga Ribeiro

Devido à sua extensão, a mancha urbana conurbada foi dividida por regiões, iniciando pelo Vetor Norte (pesquisa concluída em março de 2014). Como sequência, está em andamento a investigação dos espaços livres existentes na área conurbada do Vetor Oeste da RMBH, por meio de análises qualitativa e quantitativa. Futuramente, serão analisados os espaços livres dos vetores Sul e Leste.

\section{PROCEDIMENTOS METODOLÓGICOS}

A pesquisa dos espaços livres existentes na área conurbada da $\mathrm{RMBH}$ se divide em três etapas:

- revisão bibliográfica para fundamentação teórica e pesquisa documental: legislações urbanísticas e ambientais vigentes que regulam a RMBH; são coletados dados documentais nos órgãos metropolitanos e estaduais (Agência Metropolitana de Planejamento (AMP); Instituto Estadual de Florestas (IEF); Fundação João Pinheiro (FJP); Conselho de Política Ambiental (COPAM), entre outros); para o lançamento dos dados georreferenciados pesquisados em mapas, são utilizados softwares específicos, como ArcGis, AutoCad, Qgis; para a atualização dos espaços livres, o Google Maps;

- trabalho de campo para conhecimento in loco, verificação da aplicação da legislação, compatibilização de dados e resultados finais;

- tabulação, análise dos dados levantados no trabalho em campo, elaboração de relatórios e produção de textos;

- a partir da classificação dos tipos de espaços livres identificados nos mapas, tem início a segunda etapa: trabalho de campo com visitas aos espaços identificados para o levantamento fotográfico e análise das tipologias dos espaços livres; a tabulação, a análise dos dados levantados no trabalho em campo, a elaboração de relatórios e a produção de textos são a terceira e última etapa.

A investigação se concentra nos espaços livres e na sua relação com a forma urbana da área conurbada de cada vetor da RMBH. A figura 3 demonstra a extensão da mancha conurbada e as divisões dos vetores de análise.

Em Belo Horizonte, a área urbana se estende por praticamente todo o município, razão de a análise ter se restringido às Unidades de Planejamento (UPs) (BELO HORIZONTE, 2012) - divisões espaciais do município de Belo Horizonte, definidas pelo Plano Diretor em 1996 - que fazem limite com as cidades estudadas.

No primeiro estudo, foram analisados os espaços livres da área conurbada do Vetor Norte, contendo parte dos municípios de Ribeirão das Neves, Santa Luzia, Vespasiano e as seguintes UPs de Belo Horizonte: Céu Azul, Piratininga, Mantiqueira, Serra Verde, Jaqueline, Isidoro Norte e Capitão Eduardo (figura 4). A área total selecionada corresponde, aproximadamente, a $87 \mathrm{~km}^{2}$. 


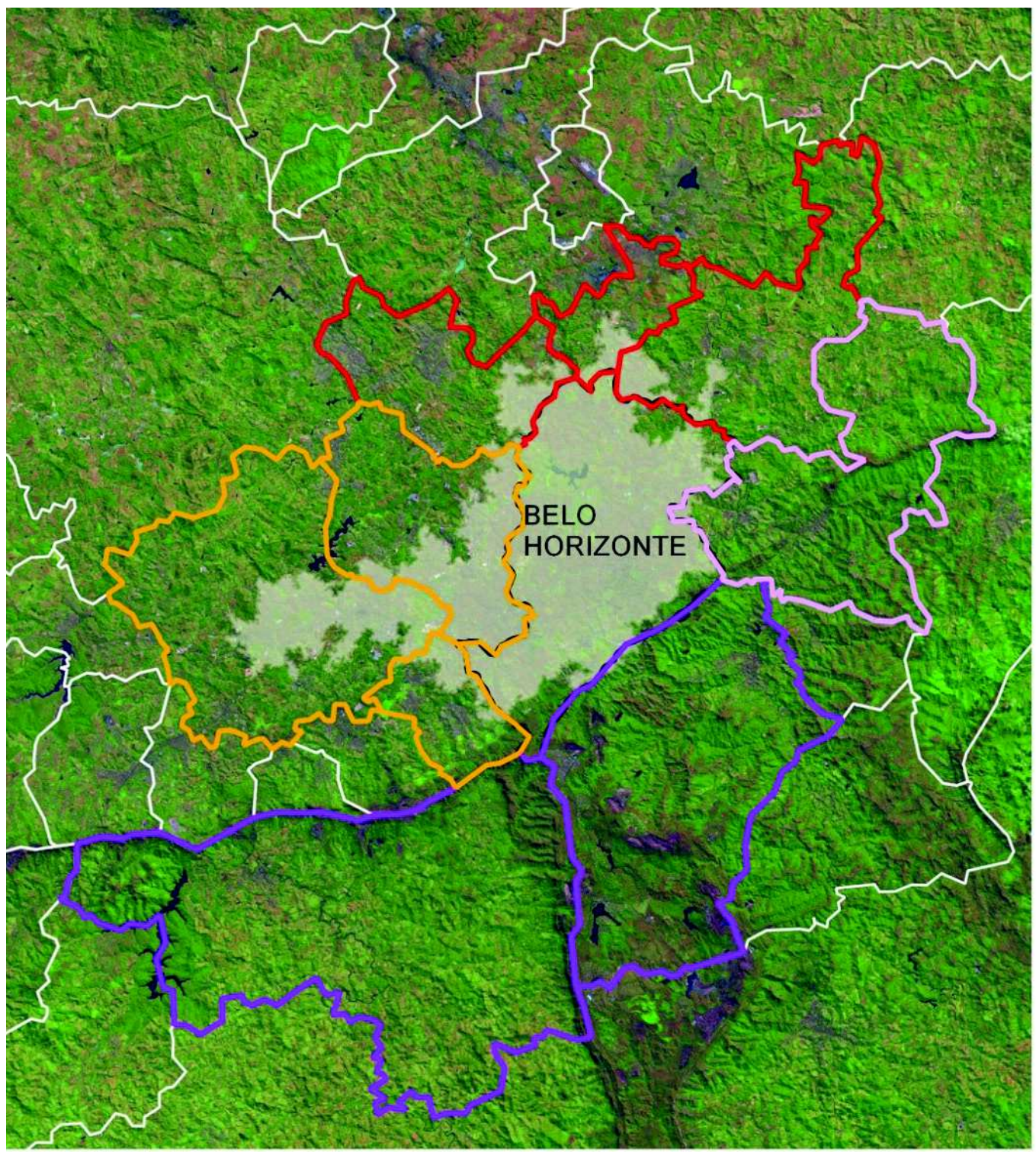

\section{Legenda}

- VETOR NORTE

- VETOR OESTE

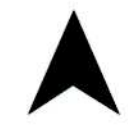

— VETOR SUL

- VETOR LESTE MANCHA URBANA CONURBADA

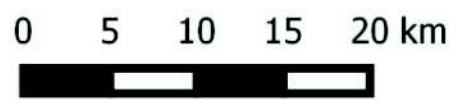

Figura 3 Imagem de satélite com a mancha urbana conurbada à metrópole e demarcação dos vetores de estudo. Fonte: Google Earth Pro - Adaptado pela equipe do LAP UFMG, 2015. 


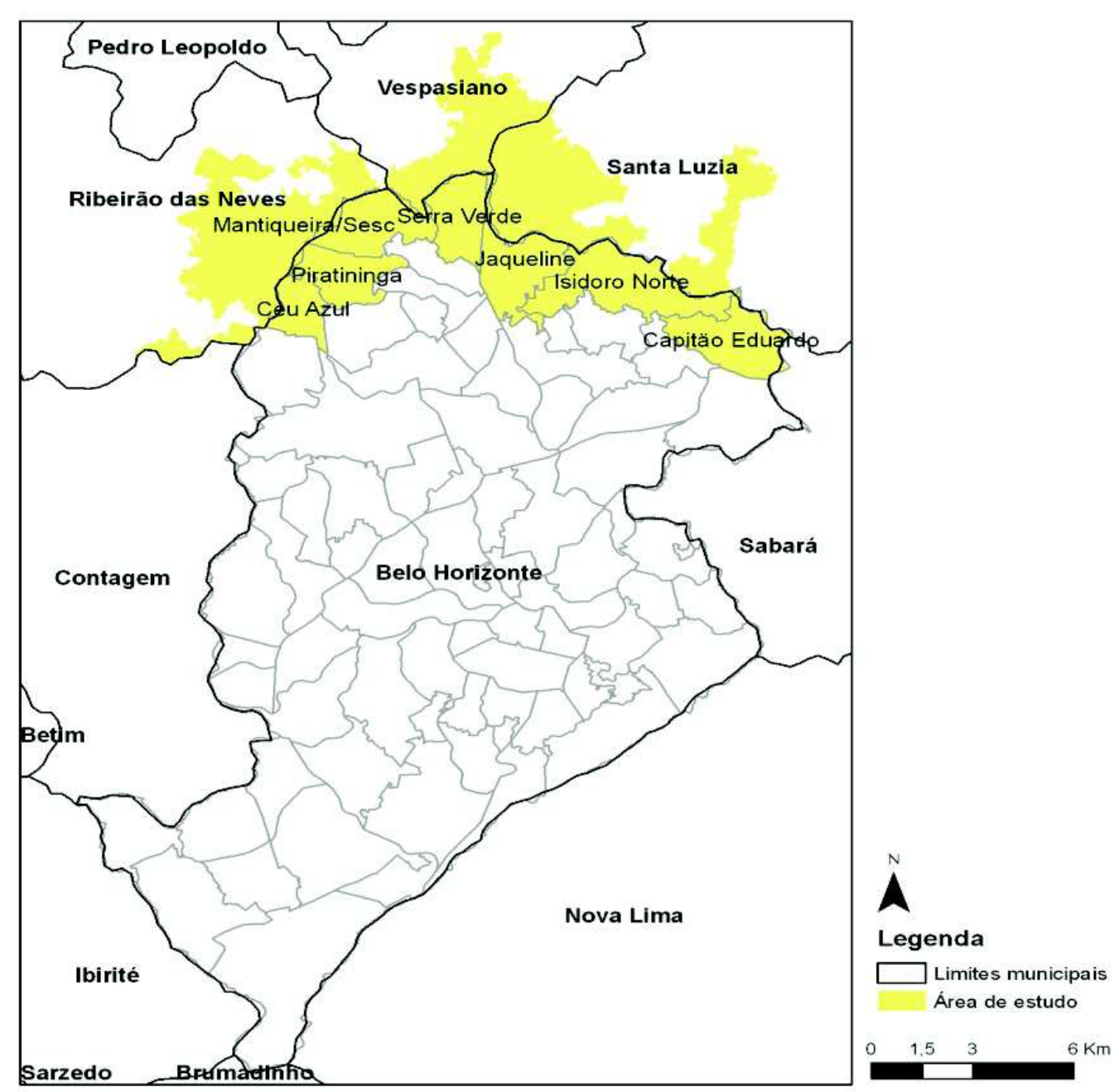

Figura 4 Delimitação da área de estudo do Vetor Norte em relação à $\mathrm{RMBH}$. Fonte: Elaborada pela equipe do LAP UFMG, 2013.

A pesquisa atual do Vetor Oeste abrange os municípios de Betim, Contagem e Ibirité, além das UPs de Belo Horizonte limítrofes à mancha conurbada, sendo elas: Garças/Braúnas, Pampulha, Confisco, Sarandi, Abílio Machado, Glória, Camargos, Santa Maria, Cabana, Bairro das Indústrias, Barreiro de Baixo, Lindeia e Jatobá (figura 5). A dimensão física territorial das áreas selecionadas para estudo dos quatro municípios corresponde à, aproximadamente, $241 \mathrm{~km}^{2}$.

A pesquisa foi iniciada por revisão bibliográfica e documental, levantamento de dados por meio de imagens de satélite e legislações pertinentes, possibilitando uma avaliação parcial da localização dos espaços livres. A próxima etapa consiste na classificação das áreas: propriedade (público e privada) e características físicas e biológicas. Pretende-se, futuramente, aplicar a mesma metodologia de pesquisa para os vetores Sul (Brumadinho e Nova Lima) e Leste (Sabará), que completarão toda a área conurbada da $\mathrm{RMBH}$. 


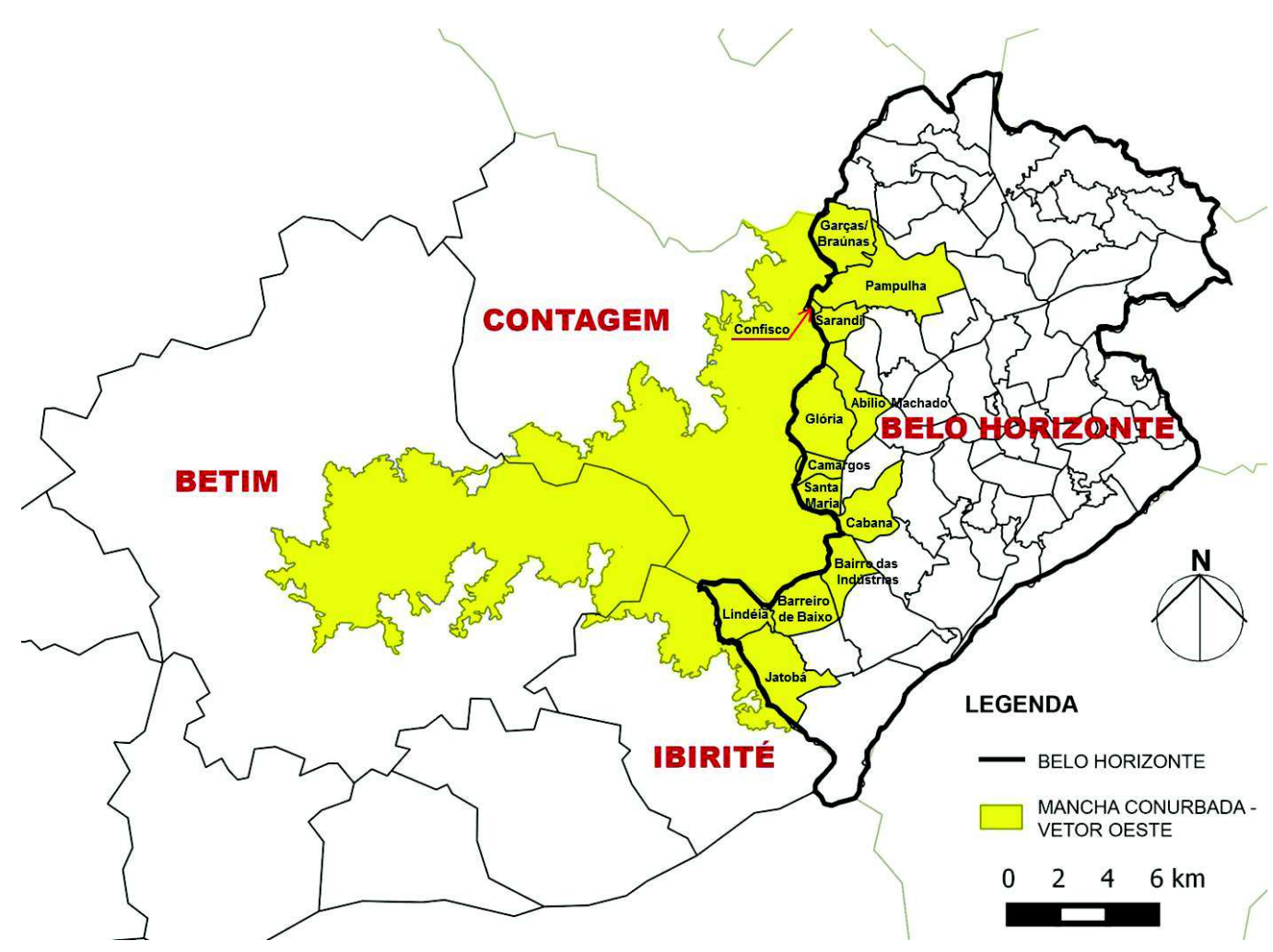

Figura 5 Delimitação da área de estudo do Vetor Oeste em relação à RMBH. Fonte: Elaborada pela equipe do LAP UFMG, 2015.

\section{RESULTADOS PARCIAIS DO VETOR NORTE DA RMBH}

A figura 6 apresenta o mapa síntese com a identificação dos espaços livres públicos do Vetor Norte da mancha conurbada da RMBH, elaborado após o levantamento de campo e a triangulação dos dados. Nota-se que $8,54 \%\left(7,5 \mathrm{~km}^{2}\right)$ da área de estudo $\left(87 \mathrm{~km}^{2}\right)$ equivale às classes de espaços livres e, quanto à divisão por municípios, Belo Horizonte concentra 97,2\% da área total de espaços livres públicos, enquanto Ribeirão das Neves, Santa Luzia e Vespasiano têm, respectivamente, 0,9\%, 1,5\% e 0,4\% da área correspondente a esses espaços.

Quanto à tipologia de espaços livres públicos, as unidades de conservação, que estão concentradas em Belo Horizonte, corresponderam a 88,3\% (6,57 km²). A outra tipologia que teve maior representatividade quanto à área foi o cemitério, também situado em Belo Horizonte e com área equivalente a $0,5 \mathrm{~km}^{2}$ (7,1\% do total da área de espaços livres públicos). Em relação à quantidade de elementos identificados por município (tabela 1), dos 83 espaços identificados, Belo Horizonte conta com 33 unidades, enquanto Ribeirão das Neves e Santa Luzia possuem, respectivamente, 20 e 25 espaços livres públicos. Vespasiano, por sua vez, tem apenas 5 unidades.

A tipologia "praça" foi a que contabilizou maior número de unidades, apesar de sua área corresponder a apenas $1,3 \%\left(0,1 \mathrm{~km}^{2}\right)$ do total. Da porcentagem total de área de cada tipologia de espaços livres, Belo Horizonte concentra 100\% das áreas 
Marieta Cardoso Maciel, Natalia Achcar Monteiro Silva, Mirelli Borges Medeiros,

Priscila Schiavo Gomes da Costa e Renata Carolina Fraga Ribeiro

de unidades de conservação, cemitérios, parques e trevos. Quanto às praças, $51 \%$ das áreas dessa tipologia estão localizadas em Santa Luzia, assim como 45\% das áreas de campos de futebol.

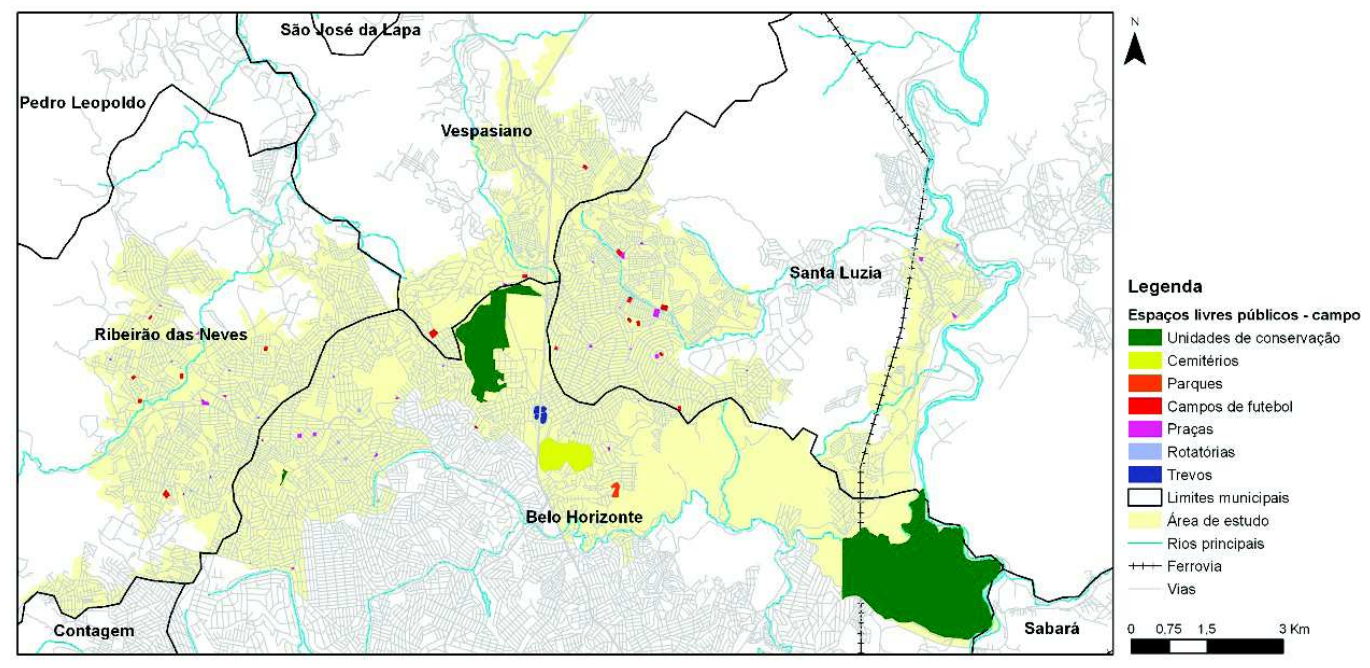

Figura 6 Mapa dos espaços livres públicos identificados na área de estudo do Vetor Norte a partir do trabalho de campo.

Fonte: Elaborada pela equipe do LAP UFMG, 2014.

Tabela 1 Quantidade de Elementos de Tipologias de Espaços Livres Públicos Identificados por Município no Vetor Norte após Trabalho de Campo

\begin{tabular}{|c|c|c|c|c|c|}
\hline \multirow{2}{*}{$\begin{array}{l}\text { Tipologias de espaços } \\
\text { livres públicos }\end{array}$} & \multicolumn{5}{|c|}{ Número de elementos por município } \\
\hline & $\begin{array}{c}\text { Belo } \\
\text { Horizonte } \\
\end{array}$ & $\begin{array}{c}\text { Ribeirão } \\
\text { das Neves }\end{array}$ & Santa Luzia & Vespasiano & Total \\
\hline Praças & 12 & 11 & 13 & 1 & 37 \\
\hline Rotatórias & 11 & 3 & 3 & 1 & 18 \\
\hline Unidades de conservação & 3 & 0 & 0 & 0 & 3 \\
\hline Campos de futebol & 1 & 6 & 9 & 3 & 19 \\
\hline Cemitérios & 1 & 0 & 0 & 0 & 1 \\
\hline Parques & 1 & 0 & 0 & 0 & 1 \\
\hline Trevos & 4 & 0 & 0 & 0 & 4 \\
\hline Total & 33 & 20 & 25 & 5 & 83 \\
\hline
\end{tabular}

Fonte: Elaborada pela equipe do LAP UFMG, 2014.

\section{RESULTADOS PARCIAIS: VETOR OESTE DA RMBH}

Em relação ao levantamento prévio do Vetor Oeste, foram identificados os seguintes espaços livres: parques, praças, rotatórias, trevos e cemitérios. Na figura 7 e na tabela 2, observa-se que a quantidade de áreas demarcadas é muito superior ao que foi mapeado no Vetor Norte, e que diversas ainda não foram classificadas, devido à 
Os Espaços Livres Públicos da Região Metropolitana de Belo Horizonte (MG): Área Conurbada do Vetor Oeste

falta de informações oficiais disponibilizadas pelas prefeituras municipais, o que será confirmado com o levantamento de campo.

Tabela 2 Quantidade de Elementos de Tipologias de Espaços Livres Identificados Previamente por Município no Vetor Oeste

\begin{tabular}{l|c|c|c|c|c}
\hline \multirow{2}{*}{$\begin{array}{c}\text { Tipologias de espaços } \\
\text { livres públicos }\end{array}$} & \multicolumn{5}{|c}{ Número de elementos por município } \\
\cline { 2 - 6 } & $\begin{array}{c}\text { Belo } \\
\text { Horizonte }\end{array}$ & Betim & Contagem & lbirité & Total \\
\hline Praças & 134 & 55 & 61 & 12 & 262 \\
\hline Rotatórias & 18 & 12 & 17 & 2 & 49 \\
\hline Cemitérios & 1 & 0 & 1 & 0 & 2 \\
\hline Parques & 8 & 3 & 2 & 3 & 16 \\
\hline Trevos & 3 & 35 & 19 & 0 & 57 \\
\hline Não classificados & 43 & 99 & 59 & 13 & 214 \\
\hline Total & 207 & 204 & 159 & 30 & 600 \\
\hline
\end{tabular}

Fonte: Elaborada pela equipe do LAP UFMG, 2015.

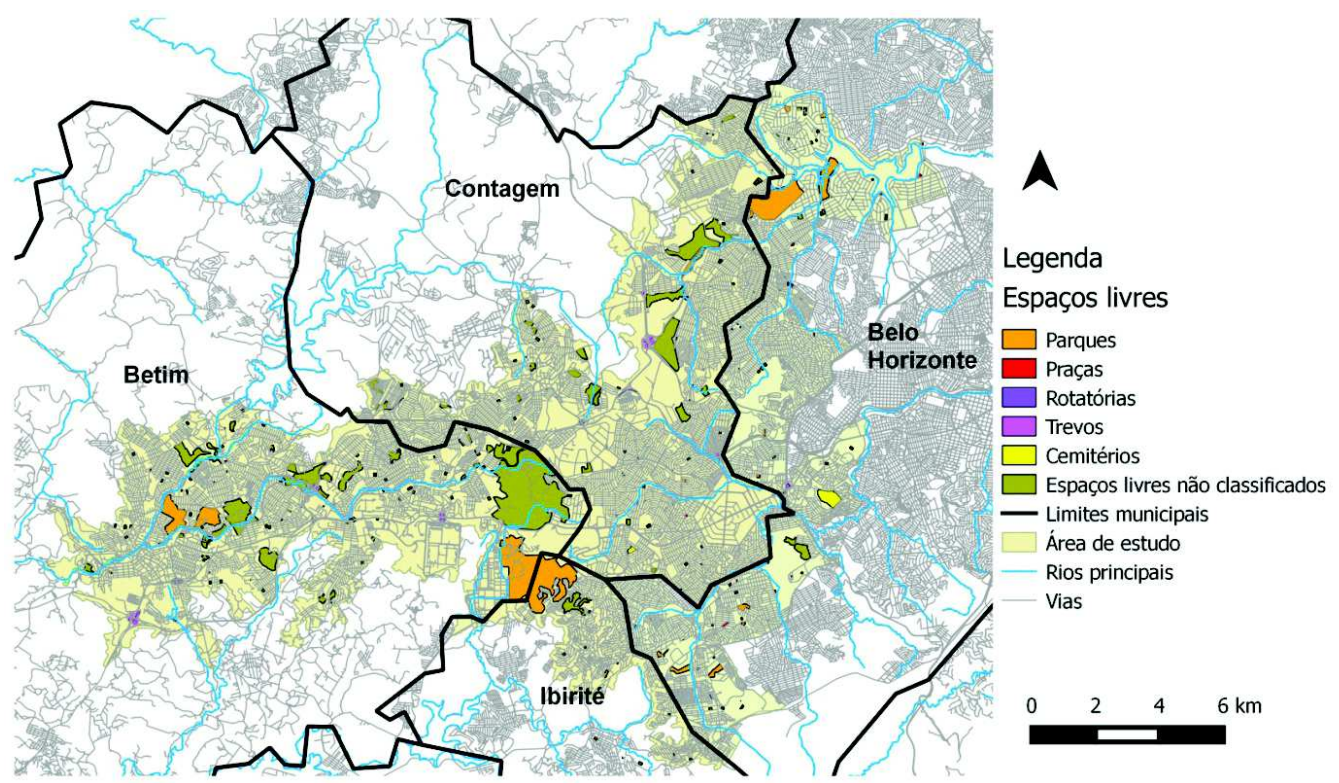

Figura 7 Mapa dos espaços livres identificados previamente na área de estudo do Vetor Oeste a partir de imagens de satélite.

Fonte: Elaborada pela equipe do LAP UFMG, 2015.

Em função das dimensões da área de estudo, ainda não foram finalizados os cálculos de áreas por tipologias e por municípios. Já em termos quantitativos, Belo Horizonte possui a maioria dos espaços livres de uso público, com uma considerável predominância de praças, sendo também a cidade com mais parques. A maior parte dos espaços ainda não classificados está em Contagem, seguido por Betim, onde se encontra a maioria dos trevos - o que pode ser justificado pela grande malha rodoviária existente. 
Marieta Cardoso Maciel, Natalia Achcar Monteiro Silva, Mirelli Borges Medeiros, Priscila Schiavo Gomes da Costa e Renata Carolina Fraga Ribeiro

\section{CONSIDERAÇÕES FINAIS}

Este artigo teve como objetivo principal apresentar as investigações quantitativas sobre os espaços livres públicos da mancha conurbada da RMBH. Os trabalhos tiveram início pelo Vetor Norte e foi constatada uma heterogeneidade da sua distribuição espacial. Na área que corresponde à cidade de Belo Horizonte, está localizada a maior concentração dos espaços livres públicos (97,2\%). As áreas equivalentes aos municípios de Ribeirão das Neves, Santa Luzia e Vespasiano, por sua vez, contribuem com menos de $3 \%$ dos espaços livres públicos identificados - sendo importante ressaltar que as administrações municipais dos mesmos possuem deficiências nas legislações de proteção dos espaços livres no território tanto em áreas urbanas, quanto rurais.

No relatório final da pesquisa do Vetor Norte, sugere-se a elaboração de um plano diretor de ordenamento territorial que contenha instrumentos adequados para implementação e monitoramento, visando à conservação e ampliação dos espaços livres públicos (praças e parques) e de Áreas de Preservação Permanente (APPs), como nascentes, cursos d'água, áreas vegetadas, topos de morro e com altas declividades sem condições de ocupação. No caso do Vetor Oeste, os dados coletados e analisados até o momento são preliminares e também demonstram uma heterogeneidade da distribuição espacial dos espaços livres de uso público.

Esta pesquisa pretende, assim, contribuir para a arquitetura e o urbanismo, enfatizando a relação entre os sistemas de espaços livres e a forma urbana. Ao mesmo tempo, está inserida em demandas de investigação do poder público, podendo ser útil para a aplicação no desenvolvimento de políticas regionais que conduzam à melhoria da qualidade de vida da população.

\section{REFERÊNCIAS BIBLIOGRÁFICAS}

BELO HORIZONTE. Secretaria Municipal Adjunta de Gestão Compartilhada. Unidades de Planejanemtno de Belo Horizonte. Belo Horizonte: PBH, 2012. Disponível em: <http://gestaocompartilhada.pbh.gov.br/sites/gestaocompartilhada.pbh.gov.br/files/produtos/3_mapa_unidades_planejamento_bh_a3_0.pdf>. Acesso em: 24 mai. 2015.

BRASIL. Lei Complementar No 14, de 8 de junho de 1973. Estabelece as regiões metropolitanas de São Paulo, Belo Horizonte, Porto Alegre, Recife, Salvador, Curitiba, Belém e Fortaleza. Disponível em: <http://www.planalto.gov.br/ ccivil_03/leis/LCP/Lcp14.htm>. Acesso em: 30 mai. 2015.

IBGE. Instituto Brasileiro de Geografia e Estatística. Censo Demográfico 2010. Disponível em: <http://www.ibge. gov.br/home/estatistica/populacao/censo2010/sinopse/sinopse_tab_rm_zip.shtm>. Acesso em: 31 mai. de 2015.

MACIEL, Marieta Cardoso et al. Os espaços livres públicos do Vetor Norte da Região Metropolitana de Belo Horizonte. In: COLÓQUIO NACIONAL QUAPÁ-SEL, 9, 2014, Vitória. Disponível em: <http://quapa.fau.usp.br/wordpress/wp-content/uploads/2016/03/Os-espa\%C3\%A7os-livres-p\%C3\%BAblicos-do-vetor-norte-da-regi\%C3\%A3o-metropolitana-de-Belo-Horizonte.pdf>. Acesso em: 1 ago 2016.

(Coord.); PEREIRA COSTA, Stäel de Alvarenga; TEIXEIRA, Maria Cristina Villefort et al. Sistemas de

espaços livres e forma urbana da cidade brasileira na contemporaneidade - QUAPÁ-SEL II. (Relatório final do projeto de pesquisa financiado pela Fundação de Amparo à Pesquisa do Estado de Minas Gerais - FAPEMIG). Escola de Arquitetura, Universidade Federal de Minas Gerais, Belo Horizonte, 2014.

PEREIRA COSTA, Stäel de Alvarenga (Coord.); MACIEL, Marieta Cardoso et al. Os sistemas de espaços livres e a constituição da esfera pública contemporânea: estudos de caso em metrópoles-cidades e novas territorialidades urbanas brasileiras - Núcleo Belo Horizonte. (Relatório final do projeto de pesquisa financiado pela Fundação de 
Os Espaços Livres Públicos da Região Metropolitana de Belo Horizonte (MG): Área Conurbada do Vetor Oeste

Amparo à Pesquisa do Estado de Minas Gerais - FAPEMIG). Escola de Arquitetura, Universidade Federal de Minas Gerais, Belo Horizonte, 2009.

TEIXEIRA, Maria Cristina Villefort (Coord.); PEREIRA COSTA, Stäel de Alvarenga; MACIEL, Marieta Cardoso et al. Os elementos tipo-morfológicos das bordas metropolitanas de Belo Horizonte. (Relatório final do projeto de pesquisa financiado pela Fundação de Amparo à Pesquisa do Estado de Minas Gerais - FAPEMIG). Escola de Arquitetura, Universidade Federal de Minas Gerais, Belo Horizonte, 2012.

\section{AGRADECIMENTOS}

Os autores agradecem o apoio recebido da Fundação de Amparo à Pesquisa de Minas Gerais (FAPEMIG), do ConseIho Nacional de Desenvolvimento Tecnológico e Científico (CNPq) e da Coordenação de Aperfeiçoamento de Pessoal de Nível Superior (CAPES) para o desenvolvimento desta pesquisa e apresentação deste artigo. 